\title{
Article
}

\section{Effects of high and low cut footwear on the kinetics and 3D kinematics of basketball specific motions}

Sinclair, Jonathan Kenneth and Sant, Benjamin

Available at http://clok.uclan.ac.uk/19304/

Sinclair, Jonathan Kenneth ORCID: 0000-0002-2231-3732 and Sant, Benjamin (2018) Effects of high and low cut footwear on the kinetics and 3D kinematics of basketball specific motions. Journal of Mechanics in Medicine and Biology, 18 (01). ISSN 0219-5194

It is advisable to refer to the publisher's version if you intend to cite from the work. http://dx.doi.org/10.1142/S0219519418500045

For more information about UCLan's research in this area go to http://www.uclan.ac.uk/researchgroups/ and search for <name of research Group>.

For information about Research generally at UCLan please go to http://www.uclan.ac.uk/research/

All outputs in CLoK are protected by Intellectual Property Rights law, including Copyright law. Copyright, IPR and Moral Rights for the works on this site are retained by the individual authors and/or other copyright owners. Terms and conditions for use of this material are defined in the policies page.

\section{CLoK}

Central Lancashire online Knowledge www.clok.uclan.ac.uk

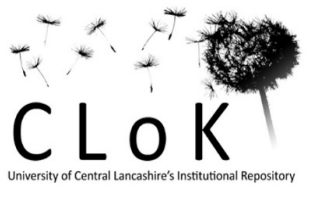




\section{Effects of high and low cut footwear on the kinetics and 3D kinematics of basketball}

specific motions.

\section{Jonathan Sinclair ${ }^{1}$ \& Benjamin Sant ${ }^{1}$}

1. Centre for Applied Sport and Exercise Sciences, School of Sport and Wellbeing,

Faculty of Health \& Wellbeing, University of Central Lancashire, Lancashire, UK.

\section{Correspondence Address:}

Dr. Jonathan Sinclair,

Darwin Building

Centre for Applied Sport Exercise and Nutritional Sciences

School of Sport and Wellbeing,

Faculty of Health \& Wellbeing,

University of Central Lancashire,

Preston

Lancashire

PR1 2HE.

e-mail: jksinclair@uclan.ac.uk

Keywords: Basketball, footwear, biomechanics, kinematics, kinetics.

\section{Abstract}


The aim of the current investigation was to examine the effects of high and low-cut basketball specific footwear, in relation to minimalist and conventional athletic footwear, on the kinetics and three-dimensional (3D) kinematics of sport specific basketball movements. Ten males performed run and $45^{\circ}$ cut movements, whilst wearing low-cut, high-cut, minimalist and conventional athletic footwear. 3D kinematics of the lower extremities were measured using an eight-camera motion analysis system, alongside the vertical rate of loading, which was obtained using an embedded force platform. Footwear differences in 3D kinematic and loading rate parameters were examined using 4 (footwear) x 2 (movement), repeated measures ANOVA. The results showed that loading rate was significantly larger in the minimalist footwear $($ run $=239.45 \&$ cut $=221.94 \mathrm{BW} / \mathrm{s}$ ), in relation to the low-cut (run $=$ $144.02 \&$ cut $=216.58 \mathrm{BW} / \mathrm{s})$, high-cut $($ run $=163.83 \&$ cut $=192.11 \mathrm{BW} / \mathrm{s})$, and conventional (run $=140.32 \&$ cut $=170.83 \mathrm{BW} / \mathrm{s}$ ) conditions. In addition, it was also revealed during the run movement that peak angles of eversion were reduced significantly when wearing the high-cut $\left(-11.14^{\circ}\right)$ footwear, compared to the low-cut $\left(-13.71^{\circ}\right)$, minimalist $\left(-13.13^{\circ}\right)$, and conventional $\left(-13.75^{\circ}\right)$ conditions. The findings from the current investigation indicate that from an injury prevention context, conventional athletic footwear may be most appropriate for basketball players who are susceptible to chronic impact related injuries, and high-cut footwear may be most suitable for players who require additional medial/ lateral ankle stability.

\section{Introduction}

Basketball is extremely popular throughout the world at all levels of play ${ }^{l}$. The sport is known to be a physiologically demanding athletic discipline ${ }^{2}$. Within a game, it is not uncommon for players to cover distances in excess of $6 \mathrm{~km}$ using a variety of exertions with different intensities that include running, jumping and changes of direction. Over the course 
of a competitive season, a player may undertake over 60 games which in combination with regular practice sessions place high physical and mechanical demands on competitive players 3 .

Basketball due to its fundamentally non-contact nature, was traditionally considered to be a relatively safe sport which was associated with a low risk from injury ${ }^{4}$. Nonetheless, in recent years with the advancement of aetiological research methodologies, basketball has gained more attention from the scientific community in regards to injury surveillance. This has demonstrated that the injury rate in basketball is relatively high in relation to other athletic disciplines. Aetiological information indicates that a total of 11.6 injuries occur per 1000 appearances, with the vast majority $(65 \%)$ of these injuries being confined to the lower extremities ${ }^{5}$.

Appropriate footwear selection has been cited as a mechanism by which the high incidence of injures in basketball players may be controlled ${ }^{6}$. The high physical demands of basketball aligned with the array of dynamic movements that are utilized within game, basketball footwear must satisfy a broad range of mechanical requirements such as traction, support, stability and shock attenuation ${ }^{7}$. Basketball footwear is available from a range of manufacturers with different design characteristics. Traditionally basketball specific footwear designs were designed with high-cut ankle supports in order to promote lateral stability during landing tasks ${ }^{8}$. However, in recent year's low-cut footwear have also been introduced at both professional and amateur levels that are selected based on individual preference. In addition, recreational level basketball players often utilize low-cut athletic footwear which may improve shock attenuation in relation to basketball specific shoes but may reduce lateral 
stability due to increased compression of the medial and lateral edges ${ }^{8}$. In relation to other athletic disciplines such as running there has been comparatively little research examining the efficacy of basketball specific footwear.

Brizuela et al., ${ }^{9}$ examined the effects of basketball footwear with different levels of ankle support on shock attenuation during running and jumping tasks. They showed that the high support footwear was also associated with a reduced inversion/ eversion range of motion on landing. Ricard et al., ${ }^{10}$ examined the effects of high and low cut basketball footwear on the magnitude and rate of inversion using an inversion platform. They showed that the high cut condition reduced both the extent and rate of inversion. Zhang et al., ${ }^{11}$ investigated the effects of three different midsole densities on impact attenuation during step-off landing tasks. Their findings show that peak vertical ground reaction forces post foot contact were greater in the soft midsole condition. Commons \& Low, ${ }^{8}$ examined the impact kinetics and lower extremity kinematics of performing the $45^{\circ}$ cut movement in high and low-cut basketball footwear. The results showed that there were no differences in impact forces but that the high-cut footwear had a higher inversion angle at footstrike.

Currently there is a trend in court based sports including squash ${ }^{12}$, netball ${ }^{13}$ and basketball ${ }^{14}$ for players to select minimalist footwear in lieu of traditional sport specific shoes, although the clinical efficacy of minimalist footwear is not yet established for court specific motions. Sinclair et al., ${ }^{12}$ explored knee and ankle loads during the squash lunge when wearing squash specific and minimalist footwear. Their results showed that peak Achilles tendon force was significantly larger in the minimalist footwear. Sinclair et al., ${ }^{13}$ examined the effects of netball specific and minimalist footwear on the kinetics and kinematics of netball specific 
movements. Their findings showed that the loading rate and peak angle of eversion were significantly larger in the minimalist footwear. There is a lack of published research investigating the effects of different footwear on the parameters linked to the aetiology of injury development in basketball-specific movements. Thus it is evident that there is a clear lack of published work investigating the effects of typically utilized footwear on the specific kinetic and 3D kinematic parameters linked to the aetiology of injury in basketball players.

Therefore, the aim of the current investigation was to examine the influence of high and lowcut specific basketball footwear in relation to minimalist and conventional athletic footwear on the kinetics and 3-D kinematics of sport specific basketball movements. The findings from the current investigation may provide basketball players with important clinical information regarding the selection of appropriate footwear, which may ultimately help to attenuate the high incidence of lower extremity injuries.

\section{Methods}

\section{Participants}

Ten male participants, volunteered to take part in this study. All were free from musculoskeletal pathology at the time of data collection and provided written informed consent. The mean characteristics of the participants were; age $24.26 \pm 4.05$ years, height $1.77 \pm 0.07 \mathrm{~cm}$ and body mass $78.66 \pm 7.43 \mathrm{~kg}$. The procedure utilized for this investigation was approved by the University of Central Lancashire, Science, Technology, Engineering and Mathematics, ethical committee.

\section{Footwear}


The footwear used during this study consisted of minimalist (Vibram five-fingers Original; Figure 1A), high-cut (Nike Lebron XII; Figure 1B), low-cut (Nike Lebron XII Low; Figure 1C) footwear and conventional (New Balance 1260 v2; Figure 1D) (shoe size 9-10 in UK men's sizes). The minimalist footwear were rated using the minimal index scale, and received a value of $96^{15}$.

\section{@@@FIGURE1 NEARHERE @@@}

\section{Procedure}

Participants completed five repeats of two sport specific movements; run and cut in each of the four footwear conditions. To control for any order effects the order in which participants performed in each footwear/ movement condition were counterbalanced. Kinematic information from the lower extremity joints was obtained using an eight camera motion capture system (Qualisys Medical AB, Goteburg, Sweden) using a capture frequency of 250 Hz. To measure kinetic information an embedded piezoelectric force platform (Kistler National Instruments, Model 9281CA) operating at $1000 \mathrm{~Hz}$ was utilized. The kinetic and kinematic information were synchronously obtained and interfaced using Qualisys track manager.

To quantify lower extremity joint kinematics in all three planes of rotation the calibrated anatomical systems technique was utilized ${ }^{16}$. Retroreflective markers (19 mm) were positioned unilaterally allowing the; foot, shank and thigh to be defined. The foot was defined via the 1 st and 5th metatarsal heads, medial and lateral malleoli and tracked using the 
calcaneus, 1 st metatarsal and 5th metatarsal heads. The shank was defined via the medial and lateral malleoli and medial and lateral femoral epicondyles and tracked using a cluster positioned onto the shank. The thigh was defined via the medial and lateral femoral epicondyles and the hip joint centre and tracked using a cluster positioned onto the thigh. To define the pelvis additional markers were positioned onto the anterior (ASIS) and posterior (PSIS) superior iliac spines and this segment was tracked using the same markers. The hip joint centre was determined using a regression equation that uses the positions of the ASIS markers ${ }^{17}$. The centers of the ankle and knee joints were delineated as the mid-point between the malleoli and femoral epicondyle markers ${ }^{18,19}$. Each tracking cluster comprised four retroreflective markers mounted onto a thin sheath of lightweight carbon-fibre. Static calibration trials were obtained allowing for the anatomical markers to be referenced in relation to the tracking markers/ clusters. The $\mathrm{Z}$ (transverse) axis was oriented vertically from the distal segment end to the proximal segment end. The Y (coronal) axis was oriented in the segment from posterior to anterior. Finally, the $\mathrm{X}$ (sagittal) axis orientation was determined using the right hand rule and was oriented from medial to lateral.

Data were collected during the run and cut movements according to below procedures:

Run

Participants ran at $4.0 \mathrm{~m} \cdot \mathrm{s}^{-1} \pm 5 \%$ and struck the force platform with their right (dominant) limb. The average velocity of running was monitored using infra-red timing gates (SmartSpeed Ltd UK). The stance phase of running was defined as the duration over $>20 \mathrm{~N}$ of vertical force was applied to the force platform ${ }^{20}$. 
Participants completed $45^{\circ}$ sideways cut movements using an approach velocity of $4.0 \mathrm{~m} . \mathrm{s}^{-1}$ $\pm 5 \%$ striking the force platform with their right (dominant) limb. In accordance with McLean et al., ${ }^{21}$ cut angles were measured from the centre of the force plate and the corresponding line of movement was delineated using masking tape so that it was clearly evident to participants. The stance phase of the cut-movement was similarly defined as the duration over $>20 \mathrm{~N}$ of vertical force was applied to the force platform ${ }^{20}$.

\section{Processing}

Trials were processed in Qualisys Track Manager and then exported as C3D files. Kinematic parameters were quantified using Visual 3-D (C-Motion Inc, Gaithersburg, USA) after marker data was smoothed using a low-pass Butterworth 4th order zero-lag filter at a cut off frequency of $12 \mathrm{~Hz}$. Kinematics of the hip, knee, ankle and tibial segment were quantified using an $\mathrm{XYZ}$ cardan sequence of rotations (where $\mathrm{X}$ is flexion-extension; $\mathrm{Y}$ is ab-adduction and is $\mathrm{Z}$ is internal-external rotation). All data were normalized to $100 \%$ of the stance phase then processed gait trials were averaged. 3-D kinematic measures from the hip, knee and ankle which were extracted for statistical analysis were 1) angle at footstrike, 2) angle at toeoff, 3) peak angle during stance, 4) angular range of motion (ROM) from footstrike to toe-off, and 5) relative peak ROM from footstrike to peak angle. Finally, from the force platform instantaneous loading rate was calculated as the maximum increase in vertical force between adjacent data points. This parameter was normalized by dividing by the participant's bodyweight. 
Differences in kinetic and kinematic parameters between footwear were examined using 4 (footwear) x 2 (movement) repeated measures ANOVAs, with significance accepted at the

$\mathrm{p} \leq 0.05$ level $^{22}$. Effect sizes were calculated using partial eta ${ }^{2}\left(\mathrm{p}^{2}\right)$. Follow up comparisons on significant interactions were examined using simple main effects and post-hoc pairwise comparisons were conducted on all significant main effects. The data was screened for normality using a Shapiro-Wilk which confirmed that the normality assumption was met. All statistical actions were conducted using SPSS v22.0 (SPSS Inc., Chicago, USA).

\section{Results}

Tables 1-4 and figures 2-3 present the footwear differences in kinetics and kinematics during both movements. The results indicate that the experimental footwear significantly affected both kinetic and kinematic parameters.

\section{Kinetics}

For instantaneous load rate a significant main effect was shown for footwear $\left(\mathrm{P}<0.05, \mathrm{p} \eta^{2}=\right.$ .37). Post-hoc pairwise comparisons showed that instantaneous load rate was significantly larger in minimalist footwear in relation to high-cut, low-cut and conventional footwear. In addition it was also demonstrated that instantaneous load rate was significantly larger in the high and low-cut footwear in relation to the conventional condition.

@@@TABLE 1 NEAR HERE @@@

\section{Kinematics}

@@@FIGURE 2 NEARHERE @@@ 
Hip

In the sagittal plane main effects for footwear $\left(\mathrm{P}<0.05, \mathrm{p} \eta^{2}=.35\right)$ and movement $\left(\mathrm{P}<0.05, \mathrm{p} \eta^{2}\right.$ $=.45$ ) were evident for the angle at footstrike. Post-hoc pairwise comparisons for footwear indicate that the extent of flexion at footstrike was significantly larger in the conventional and low-cut footwear in relation to the high-cut and minimalist conditions. Post-hoc comparisons for movement indicate that hip flexion at footstrike was significantly larger during the cut motion. Similarly a main effect $\left(\mathrm{P}<0.05, \mathrm{p \eta}^{2}=.50\right)$ for movement was evident for the extent of peak flexion. Post-hoc analysis showed that peak flexion was significantly greater in the cut movement.

In the coronal plane a main effect for movement $\left(\mathrm{P}<0.05, \mathrm{p}^{2}=.83\right)$ was shown for the angle at footstrike. Post-hoc pairwise comparisons show that abduction was significantly greater in the cut motion. A main effect for movement $\left(\mathrm{P}<0.05, \mathrm{p}^{2}=.94\right)$ was also shown for the angle at toe-off. Post-hoc pairwise comparisons show that abduction was significantly greater in the cut motion. Similarly a main effect $\left(\mathrm{P}<0.05, \mathrm{p} \eta^{2}=.95\right)$ for movement was evident for the peak coronal plane angle. Post-hoc analysis showed that peak abduction was significantly greater in the cut movement. A movement main effect $\left(\mathrm{P}<0.05, \mathrm{p}^{2}=.58\right)$ was found for ROM. Post-hoc analysis showed that ROM was significantly greater in the cut movement. Finally, for relative ROM a main effect for movement $\left(\mathrm{P}<0.05, \mathrm{p \eta}^{2}=.61\right)$ was shown. Posthoc pairwise comparisons show relative ROM was significantly greater in the cut motion.

In the transverse plane a main effect for movement $\left(\mathrm{P}<0.05, \mathrm{p}^{2}=.57\right)$ was shown for the angle at footstrike. Post-hoc pairwise comparisons show that internal rotation was 
significantly greater in the cut motion. A main effect for movement $\left(\mathrm{P}<0.05, \mathrm{p} \eta^{2}=.94\right)$ was also shown for the angle at toe-off. Post-hoc pairwise comparisons show that abduction was significantly greater in the cut motion. For ROM main effects were evident for both footwear $\left(\mathrm{P}<0.05, \mathrm{p \eta}^{2}=.40\right)$ and movement $\left(\mathrm{P}<0.05, \mathrm{p \eta}^{2}=.50\right)$ was found for ROM. Post-hoc comparisons for footwear showed that ROM was significantly larger in the high and low-cut footwear compared to the minimalist and conventional conditions. Post-hoc analysis for movement showed that ROM was significantly greater in the cut movement. Finally, for relative ROM main effects were evident for both footwear $\left(\mathrm{P}<0.05, \mathrm{p} \eta^{2}=.42\right)$ and movement $\left(\mathrm{P}<0.05, \mathrm{p}^{2}=.60\right)$. Post-hoc comparisons for footwear showed that ROM was significantly larger in the high and low-cut footwear compared to the minimalist and conventional conditions. Post-hoc analysis for movement showed that ROM was significantly greater in the cut movement.

@@@TABLE 2 NEARHERE @@@

Knee

In the sagittal plane a main effect for movement $\left(\mathrm{P}<0.05, \mathrm{p}^{2}=.33\right)$ was evident for the angle at footstrike. Post-hoc comparisons for movement indicate that the flexion angle at footstrike was significantly larger during the cut motion. A movement main effect $\left(\mathrm{P}<0.05, \mathrm{p} \eta^{2}=.61\right)$ was evident for the angle at toe-off. Post-hoc comparisons for movement indicate that the flexion angle at toe-off was significantly larger during the cut motion. For the angle of peak knee flexion main effects were evident for both footwear $\left(\mathrm{P}<0.05, \mathrm{p}^{2}=.49\right)$ and movement $\left(\mathrm{P}<0.05, \mathrm{p \eta}^{2}=.84\right)$. Post-hoc comparisons for footwear showed that peak flexion was larger in the high and low-cut footwear compared to the minimalist condition. Post-hoc analysis for movement showed that peak knee flexion was significantly greater in the cut movement. For 
relative ROM main effects were evident for both footwear $\left(\mathrm{P}<0.05, \mathrm{p}^{2}=.37\right)$ and movement $\left(\mathrm{P}<0.05, \mathrm{p \eta}^{2}=.67\right)$. Post-hoc comparisons for footwear showed that relative ROM was larger in the high and low-cut footwear compared to the minimalist and conventional conditions. Post-hoc analysis for movement showed that relative ROM was significantly greater in the cut movement.

In the coronal plane a main effect $\left(\mathrm{P}<0.05, \mathrm{p}^{2}=.83\right)$ of movement was shown for peak abduction. Post-hoc analysis showed that peak abduction was greater in the cut movement.

In the transverse plane a main effect for movement $\left(\mathrm{P}<0.05, \mathrm{p \eta}^{2}=.44\right)$ was evident for the angle at footstrike. Post-hoc comparisons for movement indicate that the knee was significantly more externally rotated at footstrike during the run motion. For the angle at toeoff main effects were evident for both footwear $\left(\mathrm{P}<0.05, \mathrm{p} \eta^{2}=.48\right)$ and movement $(\mathrm{P}<0.05$, $\left.p \eta^{2}=.45\right)$. Post-hoc comparisons for footwear showed that external rotation was larger in the high and low-cut footwear compared to the minimalist and conventional conditions. Post-hoc analysis for movement showed that external rotation was significantly greater in the run movement. A main effect $\left(\mathrm{P}<0.05, \mathrm{p \eta}^{2}=.60\right)$ of movement was shown for peak internal rotation. Post-hoc analysis showed that peak internal rotation was greater in the cut movement. In addition, a movement main effect $\left(\mathrm{P}<0.05, \mathrm{p} \eta^{2}=.61\right)$ was found for ROM. Post-hoc analysis showed that ROM was significantly greater in the run movement.

@@@TABLE3 NEARHERE@@@

Ankle 
In the sagittal plane main effects for footwear $\left(\mathrm{P}<0.05, \mathrm{p} \eta^{2}=.34\right)$ and movement $\left(\mathrm{P}<0.05, \mathrm{p} \eta^{2}\right.$ $=.39$ ) were evident for the angle at footstrike. Post-hoc pairwise comparisons for footwear indicate that the extent of plantarflexion at footstrike was significantly larger in the minimalist footwear in relation to the low-cut, high-cut and conventional conditions. Post-hoc comparisons for movement indicate that plantarflexion at footstrike was significantly larger during the cut motion. For ROM a main effect $\left(\mathrm{P}<0.05, \mathrm{p}^{2}=.61\right)$ of footwear was found. Post-hoc analysis indicated that ROM was larger in the low-cut, high-cut and conventional footwear in relation to the minimalist condition. Finally, for relative ROM main effects were evident for both footwear $\left(\mathrm{P}<0.05, \mathrm{p}^{2}=.89\right)$ and movement $\left(\mathrm{P}<0.05, \mathrm{p} \eta^{2}=.93\right)$. Post-hoc analysis for footwear revealed that relative ROM was larger in the minimalist footwear in relation to the high-cut, low-cut and conventional conditions.

In the coronal plane a main effect of movement $\left(\mathrm{P}<0.05, \mathrm{p} \eta^{2}=.93\right)$ was evident for peak eversion. Post-hoc analyses showed that peak eversion was larger in the run movement. In addition a significant footwear/ movement interaction $\left(\mathrm{P}<0.05, \mathrm{p} \eta^{2}=.49\right)$ was also found. Follow up analyses using simple main effects indicate that a main effect was shown for footwear $\left(\mathrm{P}<0.05, \mathrm{p \eta}^{2}=.45\right)$ during the run movement. Post-hoc pairwise comparisons showed that peak eversion was significantly reduced in the high-cut footwear in comparison to the minimalist, low-cut and conventional footwear. Finally, for relative ROM main effects were evident for both footwear $\left(\mathrm{P}<0.05, \mathrm{p}^{2}=.51\right)$ and movement $\left(\mathrm{P}<0.05, \mathrm{p} \eta^{2}=.84\right)$. Posthoc analysis for footwear revealed that relative ROM was larger in the minimalist footwear in relation to the high-cut, low-cut and conventional conditions. Post-hoc analysis for movement indicates that relative ROM was larger in the run movement. 
In the transverse plane a main effect $\left(\mathrm{P}<0.05, \mathrm{p} \eta^{2}=.69\right)$ for footwear was evident for the angle at footstrike. Post-hoc analyses showed that internal rotation at footstrike was greater in the minimalist footwear in relation to the low-cut, high-cut and conventional conditions. For the angle at toe-off main effects were evident for both footwear $\left(\mathrm{P}<0.05, \mathrm{p}^{2}=.48\right)$ and movement $\left(\mathrm{P}<0.05, \mathrm{p} \eta^{2}=.92\right)$. In addition a significant footwear/ movement interaction $\left(\mathrm{P}<0.05, \mathrm{p \eta}^{2}=.59\right)$ was also found. Follow up analyses using simple main effects indicate that a main effect was shown for footwear $\left(\mathrm{P}<0.05, \mathrm{p}^{2}=.60\right)$ during the run movement. Post-hoc pairwise comparisons showed that internal rotation was significantly larger in the minimalist and low-cut footwear in relation to the high-cut and conventional conditions. In addition a main effect of movement $\left(\mathrm{P}<0.05, \mathrm{p} \eta^{2}=.98\right)$ was evident for peak internal rotation. Post-hoc analyses showed that peak internal rotation was larger in the cut movement.

\section{@@@TABLE4 NEARHERE@@@}

\section{Discussion}

The aim of the current investigation was to examine the influence of high and low-cut specific basketball footwear in relation to minimalist and conventional athletic footwear on the kinetics and 3-D kinematics of sport specific basketball movements. To the authors knowledge this represents the first comparative examination of the biomechanical effects of performing sport specific movements in different basketball footwear. The findings from this study may provide basketball players with important clinical information regarding the selection of appropriate footwear for their training and competitive requirements. 
The first key observation from the current study is that irrespective of the movement condition loading rate parameters were significantly larger in the minimalist footwear in comparison to the conventional, low-cut and high-cut footwear. This finding is in agreement with those of Sinclair et al., 13, 23, 24, which evidenced that minimalist footwear were associated with significantly increased impact loading parameters. Furthermore, it was also revealed that loading rates were significantly greater in the low and high-cut footwear in comparison to conventional footwear. It is proposed that this finding relates to the absence of midsole cushioning material in the minimalist footwear and the increased midsole stiffness in the low and high-cut conditions. This finding may be important clinically as the magnitude of impact loading is related to the aetiology of chronic injuries ${ }^{25}$. Therefore the current investigation suggests that conventional athletic footwear may reduce basketball players risk from impact related injuries compared to minimalist, low-cut and high-cut shoes conditions.

The kinematic analysis of sagittal plane ankle kinematics showed in both motions that the ankle was in a significantly more plantarflexed position at footstrike in the minimalist footwear in relation to the low-cut, high-cut and conventional conditions. This indicates that irrespective of the movement being executed that basketball players were forced to adopt a distinct footstrike modality in the minimalist footwear. This observation has been shown previously in both running and cutting motions ${ }^{13,23,24}$. This finding relates to the absence of midsole interface in the minimalist footwear compared to the low-cut, high-cut and conventional conditions, meaning running are forced to adopt a more obtuse foot contact angle in an attempt to some of the load experienced by the lower extremities ${ }^{26}$. It is not currently known what effect that this alteration may have on basketball performance in terms of successfully executing run and $45^{\circ}$ cut movements, but this is something that future work may wish to address. 
Of further importance is the observation during the run movement that the magnitude of peak eversion was significantly attenuated in the high-cut footwear in relation to the minimalist, conventional and low-cut conditions. This concurs with the observations of Sinclair et al., ${ }^{20}$ who showed that peak eversion was significantly reduced whilst wearing high-cut American football cleats during similar movements. Furthermore, the relative eversion relative ROM at the ankle was shown to be significantly larger in the minimalist footwear in relation to the high-cut, low-cut and conventional conditions. This finding similarly is in agreement with those of Sinclair et al., ${ }^{27}$ who demonstrated that eversion ROM was larger when running in minimalist footwear. It is proposed that this observation relates to the high cut nature of these footwear which provide a much more pronounced medial support mechanism in relation to the low-cut, minimalist and conventional footwear. These observations may have clinical significance as eversion parameters have been linked to the aetiology of chronic injuries ${ }^{28}$. Therefore, the current investigation indicates that high-cut footwear may be most appropriate for basketball players who are at increased risk from chronic injuries in relating to medial/ lateral ankle stability.

A potential limitation of the current investigation, is that only external measures of lower extremity loading were explored. Knee and ankle pathologies are common injuries in basketball players ${ }^{29,30}$. Previous analyses of court based activities have shown that different footwear modalities can influence biomechanical indices of internal load at these joints ${ }^{31}$. Characteristically, minimalist footwear decreases the force experienced at the knee joint in relation to court specific footwear, but also correspondingly increase the loads experienced by the ankle ${ }^{31}$. This has yet to be explored in basketball specific movements/ footwear, so it is important that this be considered in future analyses. 
In conclusion, although the biomechanical effects of basketball footwear have been examined previously, current knowledge of differences in kinetics and 3D kinematics when performing sport specific movements in high-cut, low-cut, minimalist and conventional footwear is limited. As such the current research adds additional knowledge to the current literature bae by generating an evaluation of kinetics and 3D kinematic parameters when performing running and $45^{\circ}$ cut movements in these footwear. This work shows importantly that impact loading rates were greater in minimalist compared to high-cut, low-cut, and conventional conditions. In addition it was also revealed during the run movement that peak angles of eversion were reduced significantly when wearing the high-cut footwear. Therefore the findings from the current investigation indicate that from an injury prevention context conventional athletic footwear may be most appropriate for basketball players who are susceptible to chronic impact related injuries and high-cut footwear may be most suitable for players who require additional medial/ lateral ankle stability.

\section{References}

1- Cumps, E, Verhagen R, and Meeusen R. "Prospective epidemiological study of basketball injuries during one competitive season: ankle sprains and overuse knee injuries." J Sport Sci Med 6: 204-211, 2007.

2- Montgomery PG, Pyne DB and Minahan CL. The physical and physiological demands of basketball training and competition. Int J Sports Physiol Perform. 15: 75$86,2010$.

3- Narazaki K, Berg K, Stergiou N and Chen B. Physiological demands of competitive basketball. Scand J Med Sci Sport. 19: 425-322, 2009. 
4- Gomez E, DeLee JC, and Farney, W. C. Incidence of injury in Texas girls' high school basketball. Am J Sport Med. 24: 684-687, 1996.

5- Deitch JR, Starkey C, Walters SL and Moseley JB. Injury Risk in Professional Basketball Players; A Comparison of Women's National Basketball Association and National Basketball Association Athletes. Am J Sport Med. 34: 1077-1083, 2006.

6- Shorten MR. The energetics of running and running shoes. J Biomech. 26: 41-51, 1996.

7- Caselli MA. Selecting the proper athletic shoe. Pod Manag. 25: 147-149, 2006.

8- Commons AT and Low DC. Understand-ing the effect of high-cut shoes, running shoes and prophylactic supports on ankle stability when performing a v"-cut movement. Sport Exerc Med Open J. 1: 1-7, 2014.

9- Brizuela G, Llana S, Ferrandis R and Garcia-Belenguer AC. The influence of basketball shoes with increased ankle support on shock attenuation and performance in running and jumping. J Sport Sci. 15: 505-515, 1997.

10- Ricard MD, Schulties SS and Saret JJ. Effects of high-top and low-top shoes on ankle inversion. Journal of athletic training. 35: 38-43, 2000.

11-Zhang S, Clowers K, Kohstall C, Yu YJ. Effects of various midsole densities of basketball shoes on impact attenuation during landing activities. J App Biomech. 21: 3-17, 2005.

12- Sinclair J, Bottoms L, Taylor PJ, and Mahmood K. Influence of minimalist footwear on knee and ankle loads during the squash lunge. Mov Sport Sci: 91, 77-84, 2016.

13-Sinclair J, Chockalingam N, Naemi R, and Vincent H. The effects of sport-specific and minimalist footwear on the kinetics and kinematics of three netball-specific movements. Footwear Sci. 7: 31-36, 2015. 
14- Sinclair J, and Sant B. (2016). Effects of high and low cut on Achilles tendon kinetics during basketball specific movements. FAOJ: 9, 5-11, 2016.

15-Esculier JF, Dubois B, Dionne CE, Leblond J, and Roy JS. A consensus definition and rating scale for minimalist shoes. J Foot Ankle Res: 8, 42-46, 2015.

16-Cappozzo A, Catani F, Leardini A, Benedeti MG and Della CU. Position and orientation in space of bones during movement: Anatomical frame definition and determination. Clin Biomech 10: 171-178, 1995.

17- Sinclair J, Taylor PJ, Currigan G and Hobbs SJ. The test-retest reliability of three different hip joint centre location techniques. Movement \& Sport Sci 83: 31-39, 2014.

18- Sinclair J, Hebron J and Taylor PJ. The Test-retest Reliability of Knee Joint Center Location Techniques. J App Biomech 31: 117-121, 2015.

19- Graydon R, Fewtrell D, Atkins S, and Sinclair J. The test-retest reliability of different ankle joint center location techniques, FAOJ (In press).

20-Sinclair J, Rooney E, Naemi R, Atkins S, and Chockalingam N. Effects of footwear variations on three-dimensional kinematics and tibial accelerations of specific movements in American football. J Mech Med Biol, 2016 (In press).

21- McLean SG, Huang X, Su A, and Van Den Bogert AJ. Sagittal plane biomechanics cannot injure the ACL during sidestep cutting. Clin biomech 19: 828-838, 2004.

22-Sinclair J, Taylor PJ and Hobbs SJ. Alpha level adjustments for multiple dependent variable analyses and their applicability - A review. Int Journal Sport Sci Eng 7: 17$20,2013$.

23-Sinclair J, Greenhalgh A, Edmundson CJ, Brooks D, and Hobbs SJ. The efficacy of barefoot and shod running and shoes designed to mimic barefoot running, Footwear Sci. 5: 45-53, 2013. 
24-Sinclair J, Hobbs SJ, Currigan G and Taylor PJ. A comparison of several barefoot inspired footwear models in relation to barefoot and conventional running footwear. Comp Ex Phys. 9: 13-21, 2013.

25- Whittle MW. The generation and attenuation of transient forces beneath the foot; a review. Gait Posture 10: 264-275, 1999.

26- Lieberman DE, Venkadesan M, Werbel WA, Daoud AI, D’Andrea S, Davis IS, Mang'Eni RO, Pitsiladis Y. Foot strike patterns and collision forces in habitually barefoot versus shod runners. Nature. 463: 531-535, 2010.

27-Sinclair J, Hobbs SJ, Currigan G, Giannandrea M, and Taylor PJ. Tibiocalcaneal kinematics during barefoot and in barefoot inspired shoes in comparison to conventional running footwear. Mov Sport Sci: 1, 67-75, 2014.

28- Vtasalo JT and Kvist M. Some biomechanical aspects of the foot and ankle in athletes with and without shin splints. Am J Sport Med. 11: 125-130, 1983.

29- Drakos MC, Domb B, Starkey C, Callahan L, and Allen AA. Injury in the National Basketball Association: a 17-year overview. Sport Health: A Multidisciplinary Approach, 2: 284-290, 2010.

30-McKay GD, Goldie PA, Payne WR, and Oakes BW. Ankle injuries in basketball: injury rate and risk factors. Brit J Sport Med: 35, 103-108, 2001.

31- Sinclair J, Atkins S, Taylor PJ, and Vincent H. Effects of conventional and minimalist footwear on patellofemoral and Achilles tendon kinetics during netball specific movements. Comp Ex Phys: 11, 191-199, 2015.

\section{Figures}

Figure 1: Experimental footwear $(\mathrm{A} .=$ minimalist, $\mathrm{B} .=$ high-cut, $\mathrm{C} .=$ low-cut $\&$ D. $=$ conventional). 
Figure 2: Lower extremity kinematics during running as a function of footwear (black = minimalist, grey $=$ high-cut, black dash $=$ low-cut $\&$ grey dash $=$ conventional $)(a .=$ sagittal , b. $=$ coronal \& c. $=$ transverse plane $)$.

Figure 3: Lower extremity kinematics during the cut movement as a function of footwear (black $=$ minimalist, grey $=$ high-cut, black dash $=$ low-cut $\&$ grey dash $=$ conventional $)(\mathrm{a} .=$ sagittal, b. = coronal \& c. = transverse plane $)$ 
Table 1: Instantaneous load rate as a function of both footwear and movement conditions.

\begin{tabular}{|c|c|c|c|c|c|c|c|c|c|c|c|c|c|c|c|c|}
\hline & \multicolumn{4}{|c|}{ Minimalist } & \multicolumn{4}{|c|}{ High-cut } & \multicolumn{4}{|c|}{ Low-cut } & \multicolumn{4}{|c|}{ Conventional } \\
\hline & \multicolumn{2}{|c|}{ Run } & \multicolumn{2}{|c|}{ Cut } & \multicolumn{2}{|c|}{ Run } & \multicolumn{2}{|c|}{ Cut } & \multicolumn{2}{|c|}{ Run } & \multicolumn{2}{|c|}{ Cut } & \multicolumn{2}{|c|}{ Run } & \multicolumn{2}{|c|}{ Cut } \\
\hline & Mean & $S D$ & Mean & $S D$ & Mean & $S D$ & Mean & $S D$ & Mean & $S D$ & Mean & $S D$ & Mean & $S D$ & Mean & $S D$ \\
\hline Instantaneous load rate (BW/s) & 239.45 & 151.63 & 221.94 & 73.74 & 163.83 & 81.79 & 192.11 & 119.39 & 144.02 & 67.56 & 216.58 & 109.00 & 140.32 & 66.53 & 170.83 & 73.60 \\
\hline
\end{tabular}

Table 2: Hip joint kinematics as a function of both footwear and movement conditions.

\begin{tabular}{|c|c|c|c|c|c|c|c|c|c|c|c|c|c|c|c|c|}
\hline & \multicolumn{4}{|c|}{ Minimalist } & \multicolumn{4}{|c|}{ High-cut } & \multicolumn{4}{|c|}{ Low-cut } & \multicolumn{4}{|c|}{ Conventional } \\
\hline & \multicolumn{2}{|c|}{ Run } & \multicolumn{2}{|c|}{ Cut } & \multicolumn{2}{|c|}{ Run } & \multicolumn{2}{|c|}{ Cut } & \multicolumn{2}{|c|}{ Run } & \multicolumn{2}{|c|}{ Cut } & \multicolumn{2}{|c|}{ Run } & \multicolumn{2}{|c|}{ Cut } \\
\hline & Mean & $S D$ & Mean & $S D$ & Mean & $S D$ & Mean & $S D$ & Mean & $S D$ & Mean & $S D$ & Mean & $S D$ & Mean & $S D$ \\
\hline \multicolumn{17}{|l|}{ Sagittal plane } \\
\hline Angle at footstrike $\left({ }^{\circ}\right)$ & 31.99 & 6.10 & 38.49 & 7.02 & 32.64 & 6.25 & 38.51 & 5.95 & 35.55 & 7.51 & 41.78 & 8.00 & 37.36 & 8.59 & 40.85 & 6.14 \\
\hline Angle at toe-off $\left({ }^{\circ}\right)$ & -18.56 & 5.12 & -16.57 & 5.37 & -19.62 & 5.77 & -18.00 & 4.14 & -18.72 & 6.64 & -14.42 & 5.98 & -18.86 & 7.35 & -13.91 & 6.36 \\
\hline Peak flexion $\left({ }^{\circ}\right)$ & 32.21 & 6.23 & 39.36 & 7.90 & 32.81 & 6.17 & 38.64 & 5.88 & 35.58 & 7.54 & 35.58 & 7.54 & 37.41 & 8.57 & 41.79 & 6.47 \\
\hline $\operatorname{ROM}\left({ }^{\circ}\right)$ & 50.55 & 4.41 & 55.05 & 4.96 & 41.63 & 23.43 & 56.51 & 5.29 & 54.27 & 5.76 & 56.20 & 5.37 & 56.23 & 6.97 & 54.76 & 7.82 \\
\hline Relative ROM ( ${ }^{\circ}$ ) & 0.23 & 0.32 & 0.88 & 1.71 & 0.18 & 0.32 & 0.13 & 0.20 & 0.03 & 0.06 & 0.94 & 0.38 & 0.04 & 0.09 & 0.94 & 1.54 \\
\hline \multicolumn{17}{|l|}{ Coronal plane } \\
\hline Angle at footstrike $\left({ }^{\circ}\right)$ & 2.25 & 5.48 & -6.32 & 4.52 & 0.07 & 5.05 & -8.73 & 4.55 & 1.54 & 6.15 & -4.62 & 5.97 & 3.56 & 5.23 & -3.78 & 6.26 \\
\hline Angle at toe-off $\left({ }^{\circ}\right)$ & -3.31 & 5.55 & -16.23 & 6.77 & -6.22 & 2.93 & -17.40 & 1.86 & -4.11 & 5.17 & -17.36 & 4.86 & -2.56 & 5.19 & -14.66 & 4.88 \\
\hline Peak angle $\left({ }^{\circ}\right)$ & 6.79 & 5.04 & -18.99 & 7.53 & 5.04 & 4.02 & -21.18 & 2.97 & 5.91 & 5.69 & -20.64 & 6.05 & 7.02 & 4.83 & -17.92 & 6.49 \\
\hline $\operatorname{ROM}\left({ }^{\circ}\right)$ & 6.52 & 3.42 & 10.54 & 5.86 & 7.71 & 3.44 & 9.18 & 5.27 & 6.94 & 2.61 & 12.90 & 7.01 & 6.82 & 4.35 & 11.05 & 6.16 \\
\hline Relative ROM ( ${ }^{\circ}$ ) & 4.54 & 2.60 & 12.67 & 7.19 & 4.97 & 2.17 & 12.45 & 6.53 & 4.37 & 2.24 & 16.02 & 7.61 & 3.47 & 1.99 & 14.14 & 6.97 \\
\hline \multicolumn{17}{|l|}{ Transverse plane } \\
\hline Angle at footstrike $\left({ }^{\circ}\right)$ & 2.88 & 6.00 & 6.87 & 8.36 & 5.95 & 7.20 & 11.61 & 7.51 & 5.87 & 4.62 & 11.04 & 4.10 & 2.75 & 6.67 & 7.11 & 8.17 \\
\hline Angle at toe-off $\left({ }^{\circ}\right)$ & -0.88 & 9.31 & -4.59 & 8.84 & -3.17 & 7.72 & -5.75 & 7.27 & -1.10 & 7.69 & -3.39 & 6.20 & -1.34 & 9.55 & -4.57 & 8.45 \\
\hline Peak external & -4.70 & 6.95 & -7.17 & 8.68 & -5.16 & 7.47 & -7.60 & 6.51 & -5.51 & 5.85 & -4.74 & 5.40 & -7.22 & 6.99 & -7.98 & 7.51 \\
\hline
\end{tabular}




\begin{tabular}{|c|c|c|c|c|c|c|c|c|c|c|c|c|c|c|c|c|}
\hline rotation $\left({ }^{\circ}\right)$ & & & & & & & & & & & & & & & & \\
\hline ROM ( $\left.{ }^{\circ}\right)$ & 6.02 & 3.15 & 11.69 & 5.90 & 9.80 & 5.95 & 17.36 & 4.58 & 7.95 & 6.95 & 14.57 & 5.63 & 6.59 & 5.57 & 11.96 & 5.19 \\
\hline Relative ROM ( ${ }^{\circ}$ ) & 7.58 & 2.51 & 14.03 & 4.93 & 11.11 & 4.83 & 19.21 & 4.78 & 11.38 & 5.12 & 15.78 & 4.44 & 9.97 & 4.03 & 15.09 & 4.30 \\
\hline
\end{tabular}

Table 3: Knee joint kinematics as a function of both footwear and movement conditions.

\begin{tabular}{|c|c|c|c|c|c|c|c|c|c|c|c|c|c|c|c|c|}
\hline & \multicolumn{4}{|c|}{ Minimalist } & \multicolumn{4}{|c|}{ High-cut } & \multicolumn{4}{|c|}{ Low-cut } & \multicolumn{4}{|c|}{ Conventional } \\
\hline & \multicolumn{2}{|c|}{ Run } & \multicolumn{2}{|c|}{ Cut } & \multicolumn{2}{|c|}{ Run } & \multicolumn{2}{|c|}{ Cut } & \multicolumn{2}{|c|}{ Run } & \multicolumn{2}{|c|}{ Cut } & \multicolumn{2}{|c|}{ Run } & \multicolumn{2}{|c|}{ Cut } \\
\hline & Mean & $S D$ & Mean & $S D$ & Mean & $S D$ & Mean & $S D$ & Mean & $S D$ & Mean & $S D$ & Mean & $S D$ & Mean & $S D$ \\
\hline \multicolumn{17}{|l|}{ Sagittal plane } \\
\hline Angle at footstrike $\left({ }^{\circ}\right)$ & 21.02 & 2.49 & 26.29 & 4.16 & 20.84 & 4.71 & 25.05 & 3.71 & 21.03 & 6.15 & 27.09 & 5.37 & 23.07 & 6.32 & 23.78 & 3.11 \\
\hline Angle at toe-off $\left({ }^{\circ}\right)$ & 21.11 & 5.22 & 23.44 & 7.00 & 21.73 & 4.19 & 24.81 & 6.60 & 21.28 & 4.88 & 28.57 & 4.92 & 18.16 & 3.74 & 23.87 & 6.69 \\
\hline Peak flexion $\left({ }^{\circ}\right)$ & 41.81 & 4.72 & 52.82 & 9.50 & 45.56 & 2.62 & 56.57 & 7.13 & 45.95 & 3.95 & 59.30 & 6.55 & 43.50 & 4.08 & 56.61 & 5.47 \\
\hline $\operatorname{ROM}\left({ }^{\circ}\right)$ & 6.83 & 2.58 & 7.37 & 3.84 & 5.86 & 3.36 & 5.26 & 3.62 & 8.08 & 3.44 & 5.78 & 1.78 & 9.56 & 3.53 & 7.65 & 4.34 \\
\hline Relative ROM ( $\left.{ }^{\circ}\right)$ & 20.78 & 5.83 & 26.53 & 9.27 & 24.72 & 4.85 & 31.52 & 5.49 & 24.92 & 6.96 & 32.21 & 6.05 & 20.43 & 6.49 & 32.83 & 5.68 \\
\hline \multicolumn{17}{|l|}{ Coronal plane } \\
\hline Angle at footstrike $\left({ }^{\circ}\right)$ & 2.97 & 2.57 & 2.59 & 3.19 & 3.61 & 4.16 & 3.15 & 3.04 & 4.51 & 4.70 & 2.55 & 4.17 & 2.62 & 2.53 & 1.45 & 3.38 \\
\hline Angle at toe-off $\left({ }^{\circ}\right)$ & -0.86 & 3.71 & -1.64 & 3.81 & 1.50 & 3.33 & -0.28 & 3.79 & 0.59 & 2.43 & -1.72 & 2.91 & -0.67 & 3.07 & -3.06 & 3.82 \\
\hline Peak abduction $\left({ }^{\circ}\right)$ & -2.24 & 2.56 & -4.09 & 3.62 & -1.19 & 2.50 & -4.64 & 2.35 & -1.44 & 1.11 & -6.03 & 2.52 & -2.95 & 1.96 & -6.65 & 2.14 \\
\hline $\operatorname{ROM}\left({ }^{\circ}\right)$ & 5.98 & 3.13 & 5.12 & 4.01 & 6.12 & 3.46 & 5.85 & 2.68 & 6.57 & 4.47 & 5.91 & 3.40 & 5.56 & 3.53 & 6.10 & 4.70 \\
\hline Relative ROM ( $\left.{ }^{\circ}\right)$ & 5.21 & 3.84 & 6.68 & 3.95 & 4.80 & 4.01 & 7.79 & 3.36 & 5.95 & 4.98 & 8.57 & 3.28 & 5.57 & 3.69 & 8.10 & 4.17 \\
\hline \multicolumn{17}{|l|}{ Transverse plane } \\
\hline Angle at footstrike $\left({ }^{\circ}\right)$ & -12.07 & 4.16 & -8.44 & 3.49 & 12.97 & 5.37 & 10.23 & 3.44 & 12.24 & 5.07 & -6.38 & 3.28 & -10.67 & 5.89 & -6.35 & 2.63 \\
\hline Angle at toe-off $\left({ }^{\circ}\right)$ & -2.88 & 8.36 & -2.07 & 6.71 & -6.85 & 8.03 & -6.98 & 7.86 & -5.58 & 7.60 & -3.40 & 5.51 & -4.13 & 8.01 & -0.92 & 6.22 \\
\hline $\begin{array}{l}\text { Peak external } \\
\text { rotation }\left({ }^{\circ}\right)\end{array}$ & 7.16 & 3.87 & 8.10 & 3.44 & 3.15 & 3.46 & 6.27 & 4.10 & 5.62 & 3.14 & 7.64 & 2.71 & 7.32 & 3.68 & 10.03 & 2.78 \\
\hline
\end{tabular}




\begin{tabular}{|c|c|c|c|c|c|c|c|c|c|c|c|c|c|c|c|c|}
\hline & .97 & 93 & 6.97 & .60 & 10.37 & 6.00 & 6.6 & 4. & 9.90 & .47 & 5.2 & 9 & 10 & & 7.34 & \\
\hline & 9.23 & 3.85 & 16.54 & 1.87 & 16.12 & 4.75 & 16.51 & 4.2 & 17.87 & 4.60 & 14.0 & .6 & 18.00 & & 16.38 & \\
\hline
\end{tabular}

Table 4: Ankle joint kinematics as a function of both footwear and movement conditions.

\begin{tabular}{|c|c|c|c|c|c|c|c|c|c|c|c|c|c|c|c|c|}
\hline & \multicolumn{4}{|c|}{ Minimalist } & \multicolumn{4}{|c|}{ High-cut } & \multicolumn{4}{|c|}{ Low-cut } & \multicolumn{4}{|c|}{ Conventional } \\
\hline & \multicolumn{2}{|c|}{ Run } & \multicolumn{2}{|c|}{ Cut } & \multicolumn{2}{|c|}{ Run } & \multicolumn{2}{|c|}{ Cut } & \multicolumn{2}{|c|}{ Run } & \multicolumn{2}{|c|}{ Cut } & \multicolumn{2}{|c|}{ Run } & \multicolumn{2}{|c|}{ Cut } \\
\hline & Mean & $S D$ & Mean & $S D$ & Mean & $S D$ & Mean & $S D$ & Mean & $S D$ & Mean & $S D$ & Mean & $S D$ & Mean & $S D$ \\
\hline \multicolumn{17}{|l|}{ Sagittal plane } \\
\hline Angle at footstrike $\left({ }^{\circ}\right)$ & -9.05 & 8.20 & -15.47 & 9.89 & -3.58 & 13.41 & -8.60 & 15.02 & -0.65 & 11.86 & -6.61 & 14.03 & -1.56 & 13.69 & -6.08 & 15.02 \\
\hline Angle at toe-off $\left({ }^{\circ}\right)$ & -23.14 & 8.11 & -22.27 & 8.45 & 20.14 & 9.57 & 23.56 & 8.36 & 20.84 & 7.18 & 21.39 & 8.06 & 23.51 & 9.44 & 25.80 & 10.68 \\
\hline Peak dorsiflexion $\left({ }^{\circ}\right)$ & 14.75 & 7.27 & 17.06 & 7.60 & 16.03 & 8.34 & 17.48 & 7.04 & 16.51 & 6.98 & 16.97 & 11.29 & 16.19 & 8.88 & 17.35 & 7.90 \\
\hline $\operatorname{ROM}\left({ }^{\circ}\right)$ & 14.09 & 6.24 & 7.74 & 6.37 & 16.93 & 8.07 & 16.56 & 8.81 & 20.19 & 6.97 & 15.81 & 9.52 & 21.95 & 6.87 & 20.07 & 7.65 \\
\hline Relative ROM ( ${ }^{\circ}$ ) & 23.80 & 4.94 & 32.54 & 7.05 & 19.60 & 7.93 & 26.08 & 9.93 & 17.16 & 7.32 & 23.58 & 6.11 & 17.74 & 7.54 & 23.44 & 8.92 \\
\hline \multicolumn{17}{|l|}{ Coronal plane } \\
\hline Angle at footstrike $\left({ }^{\circ}\right)$ & 0.24 & 8.68 & -0.60 & 6.75 & -0.94 & 6.37 & -0.23 & 5.98 & -2.16 & 5.52 & -2.15 & 3.26 & -2.07 & 6.16 & -2.71 & 5.21 \\
\hline Angle at toe-off $\left({ }^{\circ}\right)$ & 2.44 & 7.51 & 1.28 & 5.66 & 2.05 & 3.92 & 2.94 & 3.81 & -0.55 & 3.92 & -0.56 & 4.20 & 0.52 & 3.51 & 2.73 & 3.09 \\
\hline Peak eversion ( $\left.{ }^{\circ}\right)$ & -13.13 & 9.39 & -8.45 & 6.21 & 11.14 & 5.06 & -3.86 & 4.45 & 13.71 & 4.17 & -5.88 & 4.13 & 13.75 & 3.34 & -6.03 & 2.91 \\
\hline $\operatorname{ROM}\left({ }^{\circ}\right)$ & 3.65 & 2.01 & 4.15 & 1.86 & 5.03 & 2.06 & 5.67 & 2.25 & 3.34 & 1.72 & 3.90 & 1.51 & 4.90 & 2.88 & 7.92 & 2.51 \\
\hline Relative ROM ( $\left.{ }^{\circ}\right)$ & 13.37 & 1.63 & 7.85 & 3.26 & 11.98 & 3.02 & 3.62 & 3.40 & 11.55 & 2.15 & 3.73 & 3.23 & 11.68 & 3.86 & 3.31 & 4.23 \\
\hline \multicolumn{17}{|l|}{ Transverse plane } \\
\hline Angle at footstrike $\left({ }^{\circ}\right)$ & -18.78 & 2.88 & -21.42 & 3.66 & 12.78 & 3.19 & $\begin{array}{c}- \\
14.45\end{array}$ & 3.38 & $\begin{array}{c}- \\
16.11\end{array}$ & 2.82 & $\begin{array}{c}- \\
16.88\end{array}$ & 4.74 & $\begin{array}{c}- \\
15.58\end{array}$ & 3.56 & $\begin{array}{c}- \\
15.87\end{array}$ & 3.85 \\
\hline Angle at toe-off $\left({ }^{\circ}\right)$ & -16 & 4.02 & -20.67 & 2.78 & -9.64 & 2.70 & 18.30 & 2.88 & 13.11 & 3.37 & 19.36 & 4.23 & 12.46 & 3.37 & 17.80 & 4.80 \\
\hline $\begin{array}{l}\text { Peak internal } \\
\text { rotation }\left({ }^{\circ}\right)\end{array}$ & -9.76 & 2.89 & -25.60 & 2.85 & -4.11 & 2.96 & 23.40 & 3.98 & -6.56 & 2.65 & $\begin{array}{c}- \\
23.51 \\
\end{array}$ & 3.03 & -7.31 & 3.01 & $\begin{array}{c}- \\
23.75 \\
\end{array}$ & 5.18 \\
\hline
\end{tabular}


$\operatorname{ROM}\left({ }^{\circ}\right)$

2.89

Relative ROM ( ${ }^{\circ}$ )

\begin{tabular}{l|l|l|l|l|l|l|}
2.89 & 2.33 & 2.64 & 0.93 & 3.52 & 2.52 & 4.05 \\
\hline 9.03 & 2.48 & 4.18 & 3.24 & 8.67 & 1.64 & 8.95
\end{tabular}

\begin{tabular}{|l|l|l|l|l|l|l|l|l|}
2.20 & 3.07 & 1.99 & 3.21 & 1.71 & 3.32 & 2.87 & 3.14 & 1.14 \\
\hline 3.91 & 9.55 & 2.20 & 6.63 & 3.73 & 8.27 & 1.52 & 7.88 & 4.26 \\
\hline
\end{tabular}

